\title{
5 \\ Sensible Qualities and Material Bodies in Descartes and Boyle
}

\author{
Lisa Downing
}

\section{Introduction}

Descartes and Boyle were the most influential proponents of strict mechanist accounts of the physical world, accounts which carried with them a distinction between primary and secondary (or sensible) qualities. For both, the distinction is a piece of natural philosophy. Nevertheless the distinction is quite differently articulated, and, especially, differently grounded in the two thinkers. For Descartes, reasoned reflection reveals to us that bodies must consist in mere extension and its modifications, and that sensible qualities as we conceive of them based on sense perception can pertain only to the mind. Just how we are supposed to arrive at this realization is, this essay will argue, a deep puzzle that brings us to the basic assumptions of Descartes' metaphysics. For Boyle, by contrast, while reflection can reveal the unique explanatory status of mechanism and, thus, the primary/secondary quality distinction, only experience can confirm its truth.

Our central focus will be on Descartes and on the question: How does he intend to remove the sensible qualities from the physical world; how does he strip them from bodies? I will try to show that Descartes has an argument that he takes to show a priori that sensible qualities cannot be attributed to the material world (as foundational qualities, or, as we conceive of them based on sense experience). The argument fails, however, leaving him with at best a partly empirical case for removing the sensible qualities, based on the purported explanatory success of his physics.

Boyle's aims, by contrast, are considerably more modest. He consistently holds that mechanism, including the distinction between primary affections and sensible qualities that is central to it, is an hypothesis whose truth could only be established as probable on the basis of experimental success. However, there are important conceptual elements to his case for the unique explanatory status of mechanism. 
It will be convenient to have a label for the view that both Descartes and Boyle are committed to denying. Both deny the existence of real corporeal sensible qualities. ${ }^{1}$ This is shorthand for the more careful characterization that both deny (1) that sensible qualities (such as color, taste, odor, heat and cold) are in bodies in any way that resembles our sensory experience of such qualities and (2) that they are in bodies as irreducible qualities, on a par with qualities such as size, shape, motion $/$ rest. $^{2}$

\section{Descartes: demoting the sensible qualities}

Descartes holds that bodies straightforwardly possess size, shape, motion, duration, position, number, and so on, but that color, smell, taste, sound, and so on cannot be attributed to bodies in this same straightforward sense (Pr I 69). ${ }^{3}$ In what follows, I will refer to qualities on this first list as geometrical qualities, and qualities on the second list as sensible qualities. ${ }^{4}$ This description of Descartes' doctrine is, of course, deliberately vague, for considerable controversy surrounds the question of the status of the sensible qualities for Descartes. What is uncontroversial is that the sensible qualities have a second-class status for Descartes: they are not intrinsic qualities distinct from, and on a par with, the geometrical ones; there are no real corporeal sensible qualities. What justification does Descartes have for demoting the sensible qualities from first-class status?

This question is of obvious interest, since it is central to the philosophical grounding that Descartes provides for his geometrical, mechanistic physics. Descartes' physics describes a material world that is uniform, differentiated into shapes and sizes only by motion. He cannot allow that sensible qualities are intrinsic, causally efficacious qualities distinct from the geometrical ones. ${ }^{5}$ He thus needs to unseat the sensible qualities, and he needs to provide some argument for doing so.

The question of how Descartes demotes the sensible qualities is certainly an obvious one, yet it is not one to which there is a well-established answer. Indeed, Descartes' justification for this move is nearly invisible—although relevant texts are easily located,

\footnotetext{
1 To be more accurate, Boyle denies this when he is speaking as a corpuscularian.

2 This leaves open, of course, the possibility that sensible qualities are in bodies as textures or arrangements of particles, which is a view that both Descartes and Boyle at least take seriously.

${ }^{3}$ References to Descartes' Principia Philosophiae are abbreviated as Pr and given by part and article number; these are reproduced in all editions. References to other texts of Descartes' are to the standard Adam and Tannery (AT) edition and to the standard English translation (CSM or CSMK). The few instances where I have departed from the CSM translation are marked with footnotes.

${ }^{4}$ Although Descartes has a version of the primary/secondary quality distinction, he does not use any version of the labels "primary quality" and "secondary quality". (Those labels are, of course, Lockean, though Boyle's terminology, as we will note below, comes close.) Descartes tends to refer to the two groups of qualities by example, e.g. "weight, colour, and all other such qualities that are perceived by the senses as being in corporeal matter" (Pr II 4). Of course, the geometrical qualities can be sensed, for Descartes: my stipulated terminology is not meant to suggest otherwise.

${ }^{5}$ Or, more simply and generally, he cannot allow that the sensible qualities are on an ontological par with the geometrical ones.
} 
it is exceedingly difficult to determine where exactly the arguments are taking place. ${ }^{6}$ In what follows, I will show that Part I of the Principles contains a serious argument for demoting the sensible qualities. I will argue for the unique importance of this argument as the only argument that Descartes gives for demoting the sensible qualities that does not, in one way or another, rely on Ockham's razor. I show that locating and identifying that argument allows for a new understanding of the argumentative structure of Principles I and II vis-à-vis the nature of bodies. On my interpretation, however, Descartes' argument relies on a highly controversial premise whose justification is left obscure by the texts. In the paper's penultimate section (section 6), I develop several Cartesian strategies for justifying this premise, evaluating their relative strengths and weaknesses. In the end, I am forced to the conclusion that none of these strategies is promising. In the process, however, we will identify one way in which Descartes' physics leans (precariously) on his metaphysics. In addition, we will gain a better appreciation of what a difficult task it is, even for Descartes, to banish sensible qualities from the physical world.

\section{Locating the argument: other arguments and Ockham's razor}

First, we need to locate the relevant arguments. It might seem that one should look to the Meditations for Descartes' justification of his conception of body, since he regarded that work as his official metaphysics (AT V 291: CSMK III 369) and he famously told Mersenne (in confidence) that it formed the foundation for all his physics (AT III 297-8: CSMK III 173). However, it is a noteworthy fact about the Meditations that it contains no argument that bodies possess no non-geometrical qualities. In the wax argument of the Second Meditation, Descartes foreshadows the geometrical conception of body, but does not attempt to establish it. In the Fifth Meditation, he shows that we have a clear and distinct conception of bodies as merely geometrical objects. From this, in the Sixth Meditation, he concludes that bodies which are extended could exist, and then, via a problematic argument from God's veracity, that such bodies do exist. Descartes warns us repeatedly that we have no reason to conclude that bodies have all the qualities that we ordinarily attribute to them on the basis of sense perception. Of course, this is not to show that they in fact lack such qualities. And, although Descartes repeatedly insinuates that we are mistaken in attributing sensible qualities such as color to bodies, he does not actually claim to have established that bodies have only geometrical qualities. ${ }^{7}$ Rather, he states his conclusion quite precisely as follows:

\footnotetext{
${ }^{6}$ Monte Cook (1996, 17, note 3) notes that Descartes' argument for the claim that bodies don't have color is surprisingly difficult to reconstruct. Jill Vance Buroker (1991) is driven to combing the Rules for an implicit justification for the move.

7 Thus I am somewhat puzzled by Daniel Garber's strategy (1992, 77, 85) of tracing all of Descartes' arguments for his minimal conception of body back to the Meditations. Of course, elements of whatever arguments Descartes can make in this regard are to be found in the Meditations, but the conclusion is not.
} 


\section{II2 PRIMARY AND SECONDARY QUALITIES}

It follows that corporeal things exist. They may not all exist in a way that exactly corresponds with my sensory grasp of them, for in many cases the grasp of the senses is very obscure and confused. But at least they possess all the properties which I clearly and distinctly understand, that is, all those which, viewed in general terms, are comprised within the subject-matter of pure mathematics.

(AT VII 80: CSM II 55)

At the end of the Meditations, then, an epistemic difference between geometrical qualities and sensible qualities has been established: we know that bodies have geometrical qualities corresponding to our clear and distinct geometrical ideas, while the status of sensible qualities is unclear. However, Descartes does not there actually reach the conclusion that bodies lack sensible qualities.

One might argue, however, that the epistemic point suffices for Descartes' purposes. Marleen Rozemond (1998, 66-75) defends Descartes' demotion of the sensible qualities in this fashion, seeing Descartes as pursuing a skeptical strategy which shifts the burden of proof to the defender of corporeal sensible qualities. I agree that there are grounds for attributing this sort of strategy to Descartes. In the rest of this section, I argue that all of Descartes' attempts to depose the sensible qualities, save one, in the end are of this same kind: they give some sort of reason to privilege geometrical qualities over sensible ones, and then rely (explicitly or implicitly) on an application of Ockham's razor, or a shifting of the burden of proof, to license the conclusion that we ought not to attribute the sensible qualities to bodies. Sections 4 and 6 of the paper will be devoted to Descartes' single attempt to justify a stronger conclusion.

Turning to the Principles, the most obvious place to look for a principled demotion of the sensible qualities is Part II, Article 4, where Descartes purports to establish that "the nature of body consists not in weight, hardness, colour, or the like, but simply in extension." Here Descartes appears to give an argument from eliminability ${ }^{8}$ for his minimal conception of body:

For as regards hardness, our sensation tells us no more than that the parts of a hard body resist the motion of our hands when they come into contact with them. If, whenever our hands moved in a given direction, all the bodies in that area were to move away at the same speed as that of our approaching hands, we should never have any sensation of hardness. And since it is quite unintelligible to suppose that, if bodies did move away in this fashion, they would thereby lose their bodily nature, it follows that this nature cannot consist in hardness. By the same reasoning it can be shown that weight, colour, and all other such qualities that are perceived by the senses as being in corporeal matter, can be removed from it, while the matter itself remains intact; it thus follows that its nature does not depend on any of these qualities.

(Pr II 4)

An obvious, if arguably just, complaint is that Descartes' thought-experiment does not amount to conceiving of a body that is not hard. ${ }^{9}$ We can set this concern aside,

\footnotetext{
${ }^{8}$ My initial exposition of this argument here derives from Garber's (1992, 77-80). In section 5 below, I offer a revised account of the role of this argument.

${ }_{9}$ Rather, it amounts to conceiving of a body whose hardness we cannot experience.
} 
however, for Descartes' argument does not depend on the construction of this particular thought experiment. He argues both here and in Pr II 11 that we can conceive of bodies as lacking the sensible qualities and that we have experienced bodies as lacking sensible qualities such as color: ${ }^{10}$

Suppose we attend to the idea we have of some body, for example a stone, and leave out everything we know to be non-essential to the nature of body: we will first of all exclude hardness, since if the stone is melted or pulverized it will lose its hardness without thereby ceasing to be a body; next we will exclude colour, since we have often seen stones so transparent as to lack colour... After all this, we will see that nothing remains in the idea of the stone except that it is something extended in length, breadth, and depth.

(Pr II 11)

This, he contends, reveals that the nature of body consists simply in extension, and that there is no real difference between space and corporeal substance. We may (with Berkeley) wish to resist Descartes' contention that we can in fact conceive of body as lacking both color and hardness; certainly we do not experience any bodies that possess only geometrical qualities. ${ }^{11}$ Supposing, however, that we grant him this, we will grant that all bodies are extended and that all it takes to be a body is to be extended. But this is not to deny that bodies may have more qualities than the merely geometrical, and may be genuinely colored and hard. Thus, if Descartes' arguments of Pr II 4 and Pr II 11 are interpreted as attempts to strip bodies of their sensible qualities, they fall short. I will suggest a somewhat different understanding of the role of these passages in Section 5.

Descartes could, of course, appeal to Ockham's razor to supplement the argument, admonishing us not to attribute corporeal qualities without necessity. Why not try to get by with attributing to bodies only the qualities we must - the essential ones? ${ }^{12}$ Indeed, something like this justification for his purely geometrical conception of body is suggested by Pr IV 203, where Descartes justifies his entire system as being (1) based on the simplest and clearest principles and (2) explanatorily adequate to the phenomena. One such phenomenon is sensory experience itself, which Descartes believes he can explain mechanistically. Supposing that Descartes can accomplish all this while attributing only geometrical qualities to bodies, it is otiose to posit any additional ones. In the end, I think we must conclude that this is the most persuasive and clearest argument that Descartes has for stripping the sensible qualities from bodies, though it is ultimately subject to a fatal objection: Descartes does not, in fact, develop a consistent and adequate physics, and his prospects would surely have been better with a less minimal starting

10 Related considerations are raised in the wax argument.

11 Thus, one way to resist the argument would be to contend that being colored or hard is essential to bodies. One of many metaphysical assumptions made by Descartes is that there could be no such basically disjunctive essential properties.

12 One might worry here that this would not allow us to attribute motion to bodies. But Descartes sees being in-motion-or-at-rest as following from what it is to be an extended substance. 
point. It is also an argument that licenses only a weak conclusion: We ought not to posit sensible qualities in bodies so long as we can get by (explanatorily) without it. Such an argument does not definitively strip bodies to their extended essence. As we will see below, Descartes does try to support a stronger conclusion elsewhere.

It may seem that Descartes himself tells us where to look for an argument in his letter to Chanut of February 26, 1649:

it must be remembered, while reading this book [the Principles] that although I consider nothing in bodies except the sizes, shapes and motions of their parts, I claim none the less to explain the nature of light and heat and all other qualities that are perceivable by the senses; for I presuppose that these qualities are only in our senses, like pleasure and pain, and not in the objects which we perceive by the senses, in which there are only certain shapes and motions which cause the sensations we call light, heat, etc. This I did not explain and prove until the end of Part Four; nevertheless it is useful to know and observe it from the beginning of the book, so as to understand it better...

(AT V 291-2: CSMK III 369)

This passage is somewhat misleading, however. In keeping with the above interpretation of the end of Part IV, what Descartes finally attempts to prove there is that his system has the resources to explain our perceptions of light, heat, etc. without positing any such qualities in objects as distinct from the geometrical qualities. This proof thus complements any prior argument that the sensible qualities are not in bodies, and in that sense it completes any such proof. It is also a necessary component of the argument from parsimony/ Ockham's razor. It is simply not true, however, that Descartes makes no earlier attempts to demote the sensible qualities, as I will show in the next section.

A stronger claim than one based merely on Ockham's razor may seem to be indicated by Pr IV 198, where Descartes argues that neurophysiology suggests that only local motion reaches the brain, that we do not understand how Scholastic substantial forms or real qualities could produce local motions, and that therefore "we have every reason to conclude that the properties in external objects to which we apply the terms light, colour, smell, taste, sound, heat and cold—as well as the other tactile qualities and even what are called 'substantial forms'- are, so far as we can see, simply various dispositions in those objects which make them able to set up various kinds of motions in our nerves". However, to the extent that this argument goes beyond an application of Ockham's razor (neurophysiology seems to require only shapes, sizes, and motions-posit no other qualities), it falls into circularity. ${ }^{13}$ For Descartes' neurophysiological views look uncontroversial only in a mechanist context-something like the mechanist principle that all corporeal interaction is by impact at contact must be presupposed. But that principle is never specifically defended by

\footnotetext{
${ }^{13}$ Keating (2004) offers a sympathetic reading of this argument, but she does not (in effect) see it as going beyond an application of Ockham's razor. She sees Descartes as merely aiming to establish that the Cartesian mechanist explanation of sense perception is more intelligible than one that posits real corporeal sensible qualities, thus, we have reason to posit only geometrical qualities.
} 
Descartes in the Principles. Rather, it simply falls out of his minimal notion of body as mere extension. ${ }^{14,15,16}$

\section{The argument for stripping the sensible qualities from bodies: Pr I 66-71}

For a definitive demotion of the sensible qualities, then, we must look elsewhere. The place to look, I suggest, is Part I of the Principles, to a set of passages that have sometimes been dismissed for their obscurity. ${ }^{17}$ To identify the argument we must examine several sections in some detail, beginning with Pr I 68:

In order to distinguish what is clear in this connection from what is obscure, we must be very careful to note that pain and color and so on are clearly and distinctly perceived when they are regarded merely as sensations or thoughts. But when they are judged to be real things existing outside our mind, there is plainly no way of understanding just what things they are. When someone says he sees color in some body or feels pain in some limb, it is the same thing as saying that he sees or feels something there such that he is completely ignorant of what it is, that is, that he does not know what he is seeing or feeling. Admittedly, if he is insufficiently attentive, he may easily convince himself that he has some knowledge of what he sees or feels, because he may suppose that it is something similar to the sensation of color or pain which he experiences within himself. But if he examines what it is that this sensation of color or pain represents [representet] as being in the colored body or the painful part, he will realize that he is wholly ignorant of it. ${ }^{18}$

We may begin by distinguishing what is clear in section 68 from what is obscure. What is clear is that the sensible qualities and pain are clearly and distinctly understood when regarded as sensations or thoughts and, further, that some sort of error is involved in projecting them externally. The exact nature of this error, however, is less clear.

14 That is, Descartes could be arguing from Ockham's razor in this fashion: My neurophysiology is the simplest and most intelligible, so we should employ it, and it implies that sensible qualities in objects are simply "various dispositions." If, on the other hand, Descartes is trying to claim that it is definitely established that only local motion reaches the brain, he is begging the question, since he has no defense of this in the Principles that is independent of the minimal notion of body as mere extension. In his discussion of fire in the World, Descartes suggests a more direct approach to a contact action principle, claiming that "it does not seem possible to conceive how one body could move another except through its own movement", and also suggesting that the only kind of change we can imagine here is motion (AT XI 7-8: CSM I 83), but he does not employ this strategy in the more rigorous context of the Principles.

${ }^{15}$ Interestingly, Descartes defends his denial of the reality of accidents in the Sixth Replies using the principle that "all sense-perception occurs through contact" (AT VII: 434: CSM II 293). In the Fourth Replies, he claims that this principle is uncontroversial and is accepted by Aristotle (AT VII 249: CSM II 173-4). But of course this principle cannot rule out the perceivability of real accidents unless it is understood in a controversially mechanist way.

${ }^{16}$ In section 7 below we will examine a more general argument that may be found in this passage, an argument also gestured at by Boyle.

17 Rozemond $(1998,77)$ calls them "unilluminating," and does not see them as containing a serious argument.

18 My translation. 
It involves a false supposition of similitude between the object and the sensation. Descartes indicates in the last sentence what is supposed to reveal to us that this supposition is false: if we consider what is represented by the sensation of color as existing in the colored body, we realize that we are wholly ignorant of it. But this point too requires further elucidation. Is Descartes' claim merely that we do not know whether bodies actually have color, and thus do not know what, if anything, our sensations manage to latch onto in the physical world?

Descartes' point is illuminated by section 70, which, like 68, I quote in its entirety for future reference:

It is clear, then, that when we say that we perceive colors in objects, this is really just the same as saying that we perceive something in objects such that we do not know what it is, but which produces in us a certain very manifest and vivid sensation which is called the sensation of color. But the way in which we make our judgement can vary very widely. For as long as we merely judge that there is something in objects (that is, in the things, of whatever kind exactly they may be, from which our sensations come to us) such that we do not know what it is, then we avoid error; indeed, we are actually guarding against error, since the recognition that we are ignorant of something makes us less liable to make any rash judgement about it. But it is quite different when we suppose that we perceive colors in objects. Of course, we do not really know what it is that we are thus calling by this name "color," and we cannot understand [intellegere] any resemblance [similitudinem] between the color that we suppose to be in objects and that which we experience in sensation. But because we do not notice this very fact, and because there are many other things, such as size, shape, number, etc., that we clearly perceive to be sensed or understood by us in a way that is not different from the way they are or at least could be in objects, we easily fall into the error of judging that what we call color in objects is entirely similar to the color which we sense, and thus of supposing that we clearly perceive what we in no way perceive. ${ }^{19}$

Descartes states that we cannot find any intelligible resemblance between the color which we suppose to be in objects and that which we experience in our sensation, although there is such an intelligible resemblance in the case of the geometrical qualities. Thus, what we are supposed to be able to observe, on reflection, is that our ideas of sensible qualities do not succeed in presenting or depicting even possible qualities of external objects.

This interpretation is further confirmed by the fact that Descartes feels obliged to explain (in Pr I 70-71) why we project our ideas of sensible qualities externally and experience no tension in doing so. We do so because (1) both sensible ideas ${ }^{20}$ and geometrical ideas are evidently produced by external bodies ${ }^{21}$ and (2) our geometrical

\footnotetext{
19 My translation.

${ }^{20}$ Here and throughout the paper I use "sensible idea" as shorthand for "(sensed) idea of a sensible quality," i.e. a sensory idea of color, taste, or smell, etc. Of course, we can have geometrical ideas, ideas of shape, etc. through sense perception.

${ }^{21}$ I set aside here the important and difficult issue of whether Descartes is fully committed to body-mind causation. His language here is certainly causal, but an occasionalist gloss on these passages would generate no obvious difficulties.
} 
ideas obviously do present possible features of external objects. This leads us to generalize unreflectively, attributing the same sort of correspondence between idea and object to sensible ideas. This supposition, however, is not merely false, in Descartes' view: it is unintelligible.

Descartes concludes in section 71 that "what we call the sensations of tastes, smells, sounds, heat, cold, light, colours and so on...do not represent anything located outside our thought," while "sizes, shapes, motions, and so on" are presented to the mind, by the geometrical ideas, "as things, or modes of things, existing (or at least capable of existing) outside thought." Thus, Descartes reaches the desired conclusion that body is mere extension, for the hypothesis that bodies have color or hardness in the way that they have shape turns out to be simply unintelligible, that is, no hypothesis at all. It is true that one might still resist by noting that Descartes has not proven that bodies have no qualities other than geometrical ones. However, since our sensations provide us with no genuine notion of other possible qualities of bodies, we cannot give any content to the proposal that bodies have color, taste, hardness, etc. as further qualities. It is thus an empty supposition. To put the point another way, while the arguments from Ockham's razor at best license the conclusion that we ought not to attribute the sensible qualities to bodies, this argument, if successful, entails that we cannot.

I take it that we have located, at this point, Descartes' only argument for the definitive demotion of the sensible qualities. The analysis of the argument, however, leaves us with a glaring question: Why did Descartes suppose that we can't coherently conceive of bodies as green, hard, or sour? What grounds could he supply for that obviously controversial claim? This question will fuel section 6 of the paper. First, however, we should consider how this analysis of $\operatorname{Pr}$ I 66-71 allows us to understand the overall structure of Pr I-II.

\section{Consequences: a revised view of the argumentative structure of Principles I-II}

Having identified Descartes' Principles I argument for demoting the sensible qualities, we are in a position to re-evaluate the overall structure of the relevant argumentation in Principles I-II, including the formerly quite unconvincing Pr II 4. In Pr I 66-71, Descartes argues that we cannot attribute sensible qualities (as basic or unreduced qualities) to bodies. The bodies under discussion here, however, are bodies conceived according to the idea of extension, geometrical bodies. That is, in Part I of the Principles, Descartes is discussing our ideas, and making a conceptual point about how some of these ideas (e.g. color and our geometrical idea of body) fail to fit together. Pr II 1 then rehearses the Meditation 6 argument that geometrical bodies exist. What is then argued in Pr II 4 is that our bodies, the natural bodies of ordinary experience, have extension as their essence. Thus, they are the geometrical bodies and, further, it then 
purportedly follows from Pr I 66-71 that we cannot suppose that they have sensible qualities resembling our sensible ideas. Pr II 4 thus does not do the work of stripping sensible qualities from bodies. What it does, rather, is to make the connection between the abstract conception of geometrical bodies and the physical bodies of ordinary experience. Now this connection is not completely new in II 4, for it is implicated in II 1. In arguing for the existence of bodies, Descartes claims not just that we have a clear and distinct perception of geometrical body/matter, but that "we appear to see clearly that the idea of it comes to us from things located outside ourselves, which it wholly resembles" (Pr II 1). This does forge (though somewhat tentatively) the connection between these geometrical conceptions and the bodies around us. Pr II 1 thus initiates, as one would expect given its position, the transition from an examination of ideas/geometrical natures to an examination of the found natural world. Pr II 4 then reinforces this connection from the other direction: If we begin with our experience and ordinary understanding of the bodies around us, we will conclude that those bodies are essentially extended, essentially geometrical. Thus, they are the geometrical bodies. Furthermore, the conclusion that purportedly follows from I 66-71, that they do not possess sensible qualities as basic qualities, is unproblematic, for we find that those qualities are optional: we experience bodies without them, and we do not need them in order to conceive of body.

\section{Three Cartesian answers to the question: Why can't I conceive of red bodies?}

Having considered some of the consequences of this interpretation of Descartes' argument for the argumentative structure of Pr I-II, I want to turn to an extended consideration of the obvious and serious problem that faces that argument. According to the interpretation that I have argued for so far, Descartes holds that sensible ideas do not present possible qualities of external objects. Our sensible ideas provide us with no way of conceiving of something external as being green, cold, sour: we just don't know what it would be for something mind-independent to be like our experience in these cases, although it is obvious what it would be for something mind-independent to be like our experience of roundness, etc. I take myself to have shown that this is Descartes' position in the Principles, that it represents a central argument for demoting the sensible qualities, and that it allows him to reach his desired conclusion: that the sensible qualities, as we experience them, are not in bodies. ${ }^{22}$ It may seem, however, that Descartes has bought this success at a high price. For surely it is counterintuitive to claim that our sensible ideas do not represent possible qualities of objects, that we do not even know what it would be for an apple to really be red. We want to say, "Of

\footnotetext{
22 Or, more strictly, that we cannot make sense of the claim that they are in bodies, and so cannot attribute them to bodies.
} 
course we know what it would be; it would be just like that!" Thus, without further elucidation, Descartes' claims seem excessively bold, even ridiculous. Why exactly would Descartes suppose that we couldn't conceive of red bodies? What is the source of the incoherence involved in projecting sensible qualities onto bodies, and how do we become aware of that incoherence? I do not think that there is a single, clear, developed answer to this question to be found in Descartes' texts. This is not to say, however, that he would have had nothing to say in response to this question. In this section, I develop and evaluate three Cartesian answers to this question. I think each of these options represents a prima facie plausible hypothesis as to how Descartes himself would have answered this question, though I will conclude that the last of them is most likely to reflect Descartes' own background views about the source of the unintelligibility in question. Unfortunately, we will find that each of these strategies for justifying Descartes' charge of unintelligibility threatens to sink under the weight of its attendant difficulties.

The structure of this discussion is complex, so let me begin with a roadmap. The organizing question is: Why does Descartes hold in the Principles that we cannot conceive of red bodies? I first consider the hypothesis that it has to do with the idea of red itself, which lands us in (I) the qualia interpretation. The alternative is that the problem Descartes sees has to do with projecting redness (and other sensible qualities) onto extended bodies. But what then is that problem? One answer is that the projection is supposed to be problematic for broadly mechanist reasons. This lands us in (II) the integrationist interpretation. Another possibility is that the problem with the projection is metaphysical. Here I contrast two different metaphysical accounts of the relation between mode and attribute. Essentialism (III) explains what's wrong with attributing redness to bodies, and so provides a basis for excluding the sensible qualities, but Descartes seems to have no good reason to assert it over the weaker unificationist account, which provides no such basis. As just indicated, I will argue that interpretation III seems to have the best Cartesian credentials, but that all three interpretations face significant philosophical problems.

The first possibility is to suppose that Descartes holds that attention to our sensible ideas reveals that they are purely qualitative, that is, mere qualia, which as such can only be attributed to a mind. For ease of reference, I will call this the qualia interpretation (I). ${ }^{23}$ On this interpretation, Descartes is claiming that once we have distanced ourselves, insofar as we can, from the unreflective habit of projection, so that we can consider the experience itself, we will see that it is a mere feeling, something locatable solely in a thinking thing. Thus, the incoherence of projecting our sensations onto bodies derives from the mere fact that bodies are non-thinking things, together with the character of our sensible ideas.

\footnotetext{
${ }^{23}$ Conversation with Daniel Sutherland led me to take the qualia interpretation more seriously than I initially had. This interpretation is also related to Garber's complete concept argument (1992, 85-89).
} 
This interpretation fits with the way in which sections 66-71 follow Descartes' outline of substance/mode ontology and his recommendations as to "how the modes of thought and extension are to be known" (Pr I 65). That is, one might think that these earlier sections prepare the reader to correctly divide the qualities into modes of extension and modes of thought, based simply on attention to their intrinsic content/ character. It fits also with Descartes' claim that color, etc. are clearly conceived when conceived of as modes of mind. It is not, however, dictated by the texts; we will see below that other options are available.

The difficulty with this option is that, as it stands, this purported contention of Descartes' is unsupported and implausible. How does introspection into "what is strictly contained in our perception ... that of which we have inner awareness" (Pr I 66) reveal color, as we experience it, to be merely mental? I do not see how to construct a particularly convincing case, here, although perhaps the most promising line available would be to argue, as Berkeley did, for internal, necessary connections between the sensible qualities and pleasure and pain. But aside from sometimes drawing an analogy between pain and the sensible qualities (Pr I 67), Descartes argues for no such connections in the Principles. ${ }^{24}$

If, however, this question (of how the purely mental character of the sensible qualities is established) is left unanswered, then we have made no progress, for the challenge can still be raised: Why isn't color like shape? The idea of shape must be attributed to mind, but shape is attributed to external objects. Color seems eligible for the same treatment. Descartes must say that this seeming is simply illusory, but on this interpretation he has provided very little to back up this contention. Furthermore, the claim that color is merely qualitative in this sense implies that color ideas are strongly non-representative, that is, not as if of objects, not externally directed. While I have argued above that Descartes is committed to the claim that sensible ideas do not succeed in representing any actual or possible sensible qualities of geometrical objects, he does not obviously need to make the stronger claim, which seems to conflict with the phenomenological facts of our experience, that they do not even purport to represent, are not even as if of objects. Moreover, Descartes' actual statements about the representationality of sensation are much more varied ${ }^{25}$ than they ought to be on the qualia interpretation, which entails a single firm negative answer to the question: Do sensible ideas represent? If, on the other hand, Descartes were to retreat to the claim that sensible ideas are partly, but not entirely qualitative, then this would not secure the result, for the question would then again arise—why can't these ideas, like geometrical ideas, represent something non-mental?

\footnotetext{
${ }^{24}$ It is interesting to note that in the World Descartes does suggest this sort of line about heat: that the sensation of heat may be a kind of pain or a kind of tickling (AT XI 9-10, CSM I 84). Descartes' point is to dissuade us from supposing that there is something in bodies which is similar to our idea of heat. Thanks to an anonymous referee for this point.

${ }^{25}$ See Simmons 1999, Wilson 1999. For an extended defense of the claim that Cartesian sensations are at least as if of objects, see De Rosa 2007.
} 
What alternative answers, then, are available to the question of why Descartes would suppose that we can't conceive of red bodies? In claiming that sensible ideas do not present possible qualities of external objects, we might see Descartes as claiming more specifically that we cannot project sensible qualities onto extended objects, that is, our sensible ideas do not present possible qualities of such objects. So interpreted, Descartes is challenging us to conceive of the manner in which the sensible qualities are to be attached to geometrical bodies. This is not circular because, as we have seen, Descartes has an independent argument that bodies are geometrical, the Meditation 6 argument from God's veracity, rehearsed in Pr II 1. The question that needs to be settled is whether they may have more qualities. Because the problem derives from a lack of fit between sensible ideas and geometrical bodies, rather than from the purported fact that the sensible ideas themselves are not externally directed, such an interpretation would be able to accommodate the evident phenomenological fact that color and shape seem alike and in the same way external. Further, Descartes would not be assuming that it should be obvious from a consideration of the sensory experience alone that sensible ideas are mere (unprojectable) sensations. Rather, a certain kind of reflection reveals the incoherence of the projection.

On this interpretation thus far, then, Descartes contends that the sensible qualities cannot intelligibly be attached to geometrical objects. But why not? My first suggestion here is that Descartes may be objecting to the projection of sensible qualities from a mechanist perspective.

We can get some intuitive purchase on this line of thought (the second interpretation, II), by considering the example of sound. What do we mean by attributing sound to an object? Do we really suppose that clanging is an intrinsic property of the bell, on a par with its shape? How should we conceive of such a quality? Where exactly should we locate it? It seems that any answer we might propose here is objectionably arbitrary: Is it in the clapper of the bell, every part of the bell, the surrounding air, and, if the latter, how far out does it extend? ${ }^{26}$ Descartes could argue that we should reach a similar state of perplexity for each of the sensible qualities. And indeed, one can work up such a state of perplexity about color: What do we mean in ascribing the greenness of our experience to the leaf? Is it a quality somehow spread out uniformly over the surface? Or does it penetrate the whole three-dimensional volume? If it does not permeate the

\footnotetext{
${ }^{26}$ Hume makes the point very strongly for taste:
}

But whatever confus'd notions we may form of an union in place betwixt an extended body, as a fig, and its particular taste, 'tis certain that, upon reflection' we must observe in this union something altogether unintelligible and contradictory. For shou'd we ask ourselves one obvious question, viz. if the taste, which we conceive to be contain'd in the circumference of the body, is in every part of it or in one only, we must quickly find ourselves at a loss, and perceive the impossibility of ever giving a satisfactory answer. We cannot reply, that 'tis only in one part: For experience convinces us, that every part has the same relish. We can as little reply that it exists in every part: For then we must suppose it figur'd and extended; which is absurd and incomprehensible.

(Hume 2000, 1.4.5.13 (156); Hume 1978, 238)

Hume holds that the same problem applies to sound and odor (but not color), that these impressions (unlike visual and tangible impressions) are not properly spatial. 
whole volume, how deep does it go? Is it present equally at every point? The parts of the leaf are (for Descartes) infinitely divisible: Are they green "all the way down"? Our sensible ideas give us insufficient guidance as to how to map sensible qualities onto extension, and thus, how to conceive of them as spatial. ${ }^{27}$

On this interpretation, what Descartes is demanding is that purported corporeal qualities be fully spatial, that is, systematically relatable (in a non-arbitrary fashion) to extension. In this sense, any purported qualities of bodies must be integrable with the geometrical ones. ${ }^{28}$ I will label this position integrationism. Thus, on this interpretation, the reason for demoting the sensible qualities is that they (purportedly) cannot be integrated with the geometrical ones, and thus cannot intelligibly be projected onto bodies.

In some respects I think this interpretation is the most attractive of the three that I offer here, in that the position attributed to Descartes stems from his mechanism, rather than an under-motivated phenomenological or metaphysical thesis. There are two problems with it, however. (1) As an interpretation, it is the most speculative of the three - there are no direct indications that Descartes sees this problem of integration as the source of the unintelligibility he proclaims. (2) The reconstructed argument from integrationism does not seem effective enough to successfully eliminate real corporeal sensible qualities. One might ask: Isn't color spatial? Why is it not systematically relatable to space? I take myself to have illustrated above that it is reasonable to have doubts about the prospects for such integration. The main difficulty for this version of Descartes' argument is that the barrier to integration of the sensible qualities is not obviously the sort of in principle barrier provided by the other two interpretations. On the contrary, the barrier seems at best merely temporary: hard thought or further empirical research might show us how the sensible qualities can be properly integrated into the geometrical conception of the world.

The last possibility that I will consider is that the problem Descartes sees with attaching sensible qualities to extended bodies is metaphysical, and that the unintelligibility that Descartes is pointing to is one he associates with Scholastic metaphysics. One of Descartes' deepest disagreements with Scholasticism lies in his rejection of real qualities; he rejects what he sees as the Scholastic picture of sensible (and other) qualities as "tacked on" to substances, as res capable of independent existence. ${ }^{29}$ Descartes

\footnotetext{
27 Arguably, these sorts of considerations, if one takes them seriously, count not just against understanding sensible qualities as intrinsic, non-geometrical qualities of bodies, but also against identifying the sensible qualities with mechanical constitutions (arrangements of parts). This wouldn't disturb Descartes in the least, however. His interest is in maintaining that our red sensations have as their source a mechanical disposition which could be called red, though it does not resemble our sensory idea of red. The above considerations just point out further aspects of that nonresemblance.

28 This fits rather nicely with the implications of Descartes' modal distinction (discussed below in connection with unificationism vs. essentialism). Descartes clearly holds that a mode of extension must be spatial, must presuppose space. Integrationism then adds that such a mode must be systematically and coherently spatial.

${ }^{29}$ See especially Menn 1995, and also Rosemond 1998, 102-138, Simmons 1994, 156-200, Garber 1992, 68-70.
} 
opposes this by requiring that all of a body's qualities be modes of its central attribute or essence. Perhaps what Descartes is doing in these sections of the Principles is supporting this requirement, which thus far seems a mere stipulation, by highlighting the unintelligibility of the alternative. Descartes' claim would then be something like this: If we try to attribute, for example, color to bodies, simply on the basis of our sensory experience of color, we are stuck with a tacked on or free-floating quality, with no intelligible relation to the body itself, thus not genuinely a quality of the body at all.

But what sort of relation is Descartes then requiring between the qualities of bodies and extension? What is necessary in order to be a mode of bodies? The problem is that there are two possibilities here- a weaker requirement and a stronger requirement for being a mode of a substance. The difficulty for Descartes, as we will see, is that only the weak requirement is well motivated, but only the strong requirement succeeds in stripping the sensible qualities from bodies.

We see the weak requirement in Descartes' explication of "modal distinction," which indicates that one-way separability is characteristic of modes: "we can clearly perceive a substance apart from the mode which we say differs from it, whereas we cannot, conversely, understand the mode apart from the substance." (Pr I 61) And the somewhat more vague language that he uses in describing the relation between mode and attribute-modes are referred to the attribute, presuppose the attribute, are not intelligible apart from the attribute ( $\operatorname{Pr} I 53)$ - coheres perfectly with the idea of oneway separability. Two-way separability, on the other hand, entails a real distinction and is characteristic of the relation between two substances, while two-way inseparability entails that at most a rational distinction is available. Descartes gives a conceptual test for separability, but he maintains that separability in clear and distinct understanding tracks separability in fact, since "... when we come to know God, we are certain that he can bring about anything of which we have a distinct understanding" (Pr I 60). I will label this understanding of modes - according to which all of a thing's qualities must be inseparable from, and inconceivable without, its attribute/essence- "unificationism," since what it requires is that all of a thing's qualities have some intrinsic connection to its essence. The essence thus is the core of the thing, unifying all of its qualities.

Sphericity thus qualifies as a mode of extension because it is inconceivable without extension, but extension is conceivable without it, that is, the extension might have some other shape instead. (Descartes has no need to claim that we can conceive of extended substance absolutely unmodified.) Descartes' geometrical qualities will qualify as modes on this understanding, since shape, position, and motion do seem conceptually dependent on extension.

The positive implications of unificationism thus fit with Descartes' commitments, but what about the negative ones? What isn't a quality of body on this view? The unificationist requirement that modes of a body must presuppose extension might eliminate some candidate qualities of bodies-for example, the Cartesian Louis de la Forge $(1666,251-2)$ argued that because the concept of force does not include the concept of extension, force cannot belong to matter. However, it is not at all clear that 
this criterion can discredit the sensible qualities as qualities of bodies. Color and hardness, in particular, do seem to presuppose extension and thus apparently meet the unificationist criterion for being a mode of body. ${ }^{30}$

I suggest that Descartes is implicitly relying on a stronger requirement for being a mode, according to which all qualities of bodies must be mere limitations of extension. ${ }^{31}$ On this view, all qualities of bodies follow from extension in that any particular extended thing must have some size, shape, and motion-or-rest. ${ }^{32}$ Another way to put this is that on this understanding of modes, only qualities that pertain to geometry are genuine qualities of bodies. In this very strong sense, the qualities of body must be "intelligible through" body's extended essence. I will call this general metaphysical view "essentialism," since it effectively requires that all of a thing's quality-types follow from its essence. ${ }^{33}$ This then is interpretation III of Descartes' answer to the question, "Why can't I conceive of red bodies?"34

Essentialism has some Cartesian credentials: Malebranche seems to invoke such an assumption in arguing that all qualities of bodies must be relations of distance. ${ }^{35}$ And essentialism does successfully strip the sensible qualities from bodies. Color, hardness, etc. are extraneous to geometry; they do not follow from or reduce to extension. Intuitively, we may say that they add something to extension, rather than merely

${ }^{30}$ As Berkeley famously argued in the case of color. The case of hardness may be trickier than that of color. If we conceive of hardness as a sort of repulsive force, arguably it can be attributed to a geometrical point. Is this to conceive of it as unextended? Not if "extended" really means "spatial".

31 Another way to try to capture Descartes' view is to say that he requires that all modes of body be something like determinates of the determinable — extension. Jorge Secada (2000) holds that for Descartes, all the real properties of substances are determinates of the essence, which is a determinable. I don't think it is helpful in interpreting Descartes, however, to lean very heavily on twentieth-century notions of determinate and determinable, which are themselves open to debate. Secada holds that mass cannot be a determinate of extension, while hope, fear, etc. are determinates of the determinable thought, but the justification for this position is not fully clear. He refers (190) to Johnson and Searle for elaboration on "determinate" and "determinable", but the technical difficulties involved in their characterizations are amply demonstrated by Sanford 2002. He suggests (14) that doubt is a determinate of thought because "to understand doubt is to understand thought or consciousness" and "if someone knows that a doubting substance exists, he thereby knows that a thinking substance exists". This allows doubt to count as a mode of thought, but it would also, arguably, allow color and hardness to count as modes of extension. Alison Simmons $(1994,162)$ also uses the language of determinate/determinable.

32 I am very close to agreement here with Simmons, who writes $(1994,190)$ that "The modes of extension are... the result of or derivable from body's having been divided into parts", and that divisibility into contiguous parts is the ratio of extension, for Descartes (189).

33 A version of the distinction between unificationism and essentialism is acknowledged by Rozemond (1998, 85-88). Dennis Des Chene $(1996,366)$ seems to regard Descartes as an essentialist who could rule out color being a mode of body by observing that the possibility of color (unlike figure) is not implied in the very idea of extension. However, he does not explain why Descartes would be entitled to assume that all the modes of extension must be implied in the very idea of extension. Similarly, Simmons (1994, 192-197) nicely diagnoses Descartes essentialism, but does not directly address the question of why he is entitled to a stronger metaphysical assumption than unificationism. Dan Kaufman argues that Descartes holds that there is a mutual entailment between modes and the principle attribute $(2008,62)$, but doesn't attempt to justify Descartes' position, nor does he consider the problems it entails that are raised below.

34 The answer is: "because redness is not intelligible through extension."

35 Malebranche 1958-67, I 122-3; Malebranche 1980, 49. 
limiting it in some way. However, essentialism poses a number of problems: First, it looks as though it may be too restrictive to fit Descartes' own views. I allowed above that motion is a mode of body on the essentialist view, but that claim can be challenged. Motion requires change over time, and time or duration is surely something over and above mere extension. Descartes can reply to this challenge, however. Extension as a nature or essence, he maintains, is nothing different from extended substance ( $\operatorname{Pr}$ I 63), and substance is necessarily connected to duration: 'since a substance cannot cease to endure without also ceasing to be, the distinction between the substance and its duration is merely a conceptual one' (Pr I 62). In effect, it seems that Descartes' position is that all of the quality-types belonging to an extended substance must be consequences of being merely an extended substance, ${ }^{36}$ and this position legitimates duration and motion-or-rest as qualities of bodies.

A second, less tractable worry concerns the application of essentialism to the realm of the mental: while hoping, fearing, and willing do presuppose thought (à la unificationism), they do not seem to follow from thought or to be mere limitations of thought. ${ }^{37,38}$ It is not obvious that there is any clear notion of mode available which excludes color as a mode of extension but includes volition (or the sensation of color!) as a mode of thought. Essentialism excludes color from bodies because color adds something not implicit in the mere notion of extension. But is this not true of fear, desire, or the sensation of color, in relation to thought?

One might wonder here about the implications of Descartes' celebrated reply to Elizabeth, which sets up a third primitive notion, in apparent tension with the Principles doctrine of two attributes:

First I consider that there are in us certain primitive notions which are as it were the patterns on the basis of which we form all our other conceptions. There are very few such notions. First, there are the most general - those of being, number, duration, etc.- which apply to everything we can conceive. Then, as regards body in particular, we have only the notion of extension, from which follows the notions of shape and motion, and as regards the soul on its own, we have only the notion of thought, in which are included the perceptions of the intellect and the inclinations of the will. Lastly, as regards the soul and the body together, we have only the notion of their union, on which depends our notion of the soul's power to move the body, and the body's power to act on the soul and cause its sensations and passions. (AT III 665: CSMK III 218) 39 $^{39}$

One might try to defend Descartes against the preceding objection by suggesting that, e.g., fear and the sensation of color do not need to follow from mere thought, because they should be referred to the third primitive notion, that of mind-body union.

\footnotetext{
${ }^{36}$ See Garber 1992 66-68.

37 In this context it is very revealing to note that Meditation 6 (AT VII, 79: CSM II, 55) specifically employs a unificationist criterion for being a mode of mind-any such mode must presuppose an act of understanding.

${ }^{38}$ Arguably, hoping and fearing, like being spherical, are too specific to follow from the attribute. Part of the difficulty here is that it isn't obvious what to count as a type. However, the objection works just as well if 'feeling an emotion' is substituted for 'fearing'.

39 Translation slightly amended from CSMK.
} 
Against this suggestion, there are two important points to be made: (1) What Descartes refers here to the mind-body union is very little-the soul's power to move the body and the body's power to act on the soul. These (unintelligible) powers are, appropriately enough, referred to the (unintelligible) notion of union, under the pressure of Elizabeth's repeated questioning. But Descartes tells us emphatically in the Principles that sensible qualities can be clearly understood as modes of mind, and he says nothing to contradict that here. (2) When describing the relation between extension and its modes, Descartes here uses language that suggests entailment: shape and motion follow from extension. Further, he says that the perceptions of the intellect and inclinations of the will are included (comprises) in thought. This statement is interestingly ambiguous. One way to read it is as claiming that perceptions of the intellect and inclinations of the will are built into the very notion of thought, analogously to the relation between extension and its modes. But this claim is problematic, and even more so for the less intellectualized modes of thought not mentioned here by Descartes. Another way to read it is as claiming that thought is a general notion which comprehends the two more specific ones: perceptions of the intellect and inclinations of the will are both kinds of thoughts. But that claim, if transposed to the realm of extension, will not do any work for him: it would be begging the question to presuppose that being red is not one way of being extended, so that red things are not a kind of extended thing. Thus, this passage provides more evidence that Descartes was an essentialist, while further illustrating the difficulty of applying essentialism to the mental realm.

The most serious worry about essentialism, however, is that it is unmotivated. Unificationism, by contrast, is very well motivated, in the context of a metaphysics built around notions of substance and essence. If modes didn't presuppose extension, they could exist independently of it, and thus would be free-floating entities, not genuinely part of the substance, little substances rather than qualities of a substance. ${ }^{40}$ Versions of this complaint are put forward by Descartes in a number of places:

I do not suppose that there are in nature any real qualities, which are attached to substances, like so many little souls to their bodies, and which are separable from them by divine power. [...] My principle reason for rejecting these real qualities is that I do not see that the human mind has any notion, or particular idea, to conceive them by; so that when we talk about them and assert their existence, we are asserting something we do not conceive and do not ourselves understand.

(AT III 468-9: CSMK III 216) $^{41}$

Of course they deny that heaviness is a substance, but that makes no difference, because they conceive it in fact as a substance since they think that it is real and that it is possible

\footnotetext{
40 This may not seem completely fair to scholastics such as Suarez, since separable here means separable by God's absolute power, which is compatible with natural inseparability. Note that Descartes is aware of this nicety, however, as is shown by the quotations below.

41 Simmons $(1994,193-194)$ cites this passage as though it made the same point as Pr I 69-70. I argue in this section that although Descartes himself very likely makes this connection, it is mistaken. The unintelligibility of real qualities does not suffice to show that attributing sensible qualities to bodies is unintelligible.
} 
by some power (namely divine power) for it to exist without the stone (AT V 223: CSMK III 358). Descartes' objections to real qualities thus amount to a persuasive argument for unificationism: the alternative is unintelligible. But why is the denial of essentialism unintelligible?

I see no obvious answer to this question in Descartes. Nevertheless, I think this interpretation is most likely to reflect his own grounds for the unintelligibility he asserts in $\operatorname{Pr} I 68$ and 70. We know that Descartes rejected real qualities as unintelligible; we know that he connected the question of the status of sensible qualities to the issue of real qualities (e.g. Pr IV 198), and his language suggests the essentialist position in more than one place. Moreover, this interpretation nicely explains the obscurity of $\operatorname{Pr} I 68$ and 70: In his published works, Descartes was habitually cautious in challenging the Scholastic establishment, so it is no surprise that an unintelligibility that purportedly characterizes Scholastic metaphysics should be indicated in an oblique fashion. ${ }^{42}$

If Descartes did suppose, however, that the only alternative to real qualities was essentialism, he was mistaken. As we have seen, unificationism suffices to rule out real qualities, but unificationism cannot eliminate the possibility that sensible qualities like color and hardness are qualities of bodies. The essentialism which can appears unmotivated (except by its utility in stripping the sensible qualities from bodies). Thus, on this interpretation Descartes either fails to distinguish unificationism and essentialism, ${ }^{43}$ or simply presupposes essentialism, despite the fact that he only has arguments for the weaker unificationist position, and despite the challenge that essentialism poses to the consistency of his metaphysics.

If this interpretation is correct, then, in effect Descartes founds his physics on an essentialist metaphysical intuition. Although, as I have argued above, Descartes has no argument to support this intuition, it is not difficult to see its appeal. All we need is one clear and distinct concept - extension (or thought) and everything else pertaining to extended (or thinking) things is simply contained in some way in that very concept. Partisans of the mechanical philosophy of the seventeenth century praised mechanist physics for its intelligibility, but it is not always easy to say what virtue is being claimed for the theory under the rubric of "intelligibility". One accomplishment of this analysis is that it illuminates a specific sort of strong intelligibility enjoyed by Descartes' system. It is less clear, of course, why we should suppose that the world conforms to this very strong ideal of intelligibility. If we demand this sort of intelligibility from our science of

\footnotetext{
42 See Garber 2001, 261. Admittedly, though, Descartes straightforwardly denounces real qualities and substantial forms at Pr IV 198. It is easy to imagine that he could not resist this bit of triumphalism as he reached the end of his magnum opus, which he hoped would replace Scholastic textbooks.

43 This suggestion may gain some support from the Scholastic context: Stephen Menn $(1995,193)$ has argued that "Suarez seems to grant a presumption in favor of reality: for God can always create an accident without its subject unless this would involve a logical contradiction, and even if we cannot clearly conceive how the accident could exist without a subject, we should assume that God can bring this about unless we clearly perceive that he cannot." Thus, if a quality adds something not implicit in what it modifies, it may look like a candidate for res-hood. Thinking along these lines, Descartes may have supposed that the only alternative to treating sensible qualities as real qualities was essentialism.
} 
bodies, and we agree that bodies are essentially extended, then Descartes' physics is the only physics, and bodies possess only geometrical qualities. Even if we are unwilling to assume essentialism, we might wish to pursue Descartes' program in order to determine whether his ideal of intelligibility can be vindicated. This, however, is again to retreat to a weaker defense of Descartes' stripping of the sensible qualities: Let's see whether the phenomena can be explained while attributing to bodies only qualities implied in the concept of extended existence.

In sum, then, I have argued that Descartes' single argument for the strong conclusion that sensible qualities (as we conceive of them based on sensory experience) cannot be attributed to bodies founders unless, with Descartes, we are willing to simply assume that all the genuine qualities of extended things must be implicit in the concept of extended existence. If we abandon this argument, we are left with several arguments for the weaker conclusion that, if possible, we ought to attribute to bodies only the clearly and distinctly conceived geometrical qualities. Sadly, the antecedent is not satisfied.

We will see in the next section that Robert Boyle, as befits his empiricist credentials, never asserts the strong conclusion, but makes his own careful case for his version of the weaker, a case grounded in a somewhat more modest ideal of intelligibility. We will also locate in both Boyle and Descartes an attempt to ground a conclusion of intermediate strength.

\section{Robert Boyle}

In some respects, Robert Boyle's treatment of the primary/secondary quality distinction is more focused and explicit than Descartes'. While Descartes' central aim in the Principles is to show how a fully developed physics flows from an understanding of the principal attribute of body, one of the main focuses of Boyle's canonical presentation of his corpuscularian physics, The Origin of Forms and Qualities According to the Corpuscular Philosophy, is the relative nature of sensible qualities. Further, Boyle provides categories that map well onto our post-Locke understanding of primary and secondary qualities. On the one hand, Boyle labels size, shape, and motion or rest the "primary affections" of bodies, which qualify and distinguish all the parts of bodies. ${ }^{44}$ On the other hand, there are the sensible qualities, whose origin Boyle explains with uncharacteristic brevity in this passage:

That yet, there being Men in the World, whose Organs of Sense are contriv'd in such differing wayes, that one Sensory is fitted to receive Impressions from some, and another from other sorts of External Objects, or Bodies without them...., the Perceptions of these Impressions are by men call'd by several Names, as Heat, Colour, Sound, Odour, and are commonly imagin'd to

\footnotetext{
${ }^{44}$ From a Lockean perspective, it is noticeable that impenetrability is not on this list. The official reason for this is that because it belongs to all matter qua matter it does not serve to diversify bodies.
} 
proceed from certain distinct and peculiar Qualities in the External Object, which have some resemblance to the Ideas, their action upon the Senses excites in the Mind; though indeed all these Sensible Qualities, and the rest that are to be met with in the Bodies without us, are but the Effects or Consequents of the above mentioned primary Affections of Matter, whose Operations are diversify'd according to the nature of the Sensories, or other Bodies they work upon.

(Works V 334: S 51-52) ${ }^{45}$

The passage gives the impression that "red" names a perception/idea, but it is far from clear that this is Boyle's considered view. ${ }^{46}$ Boyle's main interest in discussing the status of the sensible qualities lies in dissuading us from the "commonly imagined" view outlined above. ${ }^{47}$ Where exactly we should say that redness itself lies is of less interest to him, though he is very clear in Origin of Forms and Qualities that redness, along with the other sensible qualities, arises from a relation between bodies and perceivers. $^{48}$

As with Descartes, we should focus on the question: What exactly is the basis for rejecting the commonly imagined view that redness, as we imagine it based on sense perception, is actually in bodies? The most obvious answer to be found to this question in Boyle is attractively straightforward: It is simply part of the corpuscularian doctrine that sensible qualities are not basic qualities, distinct from, but on a par with, size, shape, motion/rest. And the corpuscularian doctrine is put forward as an hypothesis, to be vindicated by its application to experience:

[Corpuscularianism] is to be Collated with, and to be either Confirmed, or Disproved by, the Historicall Truths, that will be deliver'd concerning Particular Qualities. (Works V 305: S 18)

Thus Boyle officially refrains from asserting the truth of corpuscularianism, on the grounds that the verdict of experience is not yet in.

So far, then, we have located only a purely hypothetical endorsement of the primary/secondary quality distinction: If the corpuscularian hypothesis is correct, there are no real corporeal sensible qualities. Despite his habitual diffidence, however, Boyle makes claims about corpuscularianism and sensible qualities that go beyond this mild hypotheticalism. Even in Origin of Forms and Qualities, where the overall stance is

\footnotetext{
45 References to Boyle are to the standard edition of Boyle's works, Boyle 1999-2000, and are given by volume and page number and abbreviated as Works. Where the cited passage also occurs in the readily available Boyle 1991, I give that page reference as well, abbreviated as S.

46 As Anstey notes (2000, 92-94), when Boyle treats color on its own (as opposed to discussing all the sensible qualities as such), he seems inclined to regard it as a modification of light.

47 Whence the "commonly imagined" view? As Anstey emphasizes (2000, 95), given the anti-Aristotelian context of the Origin of Forms and Qualities, Boyle surely has in mind here Scholastic doctrines of real qualities. Nevertheless, I think that Boyle, like Descartes, is also countering the naïve view that bodies are really red as they appear to be, and their redness is on a par with their shape.

48 Boyle specifically endorses the thesis that in a world without perceivers, bodies would not actually be colored, though he allows that we might say that that bodies in such a world would be "dispositively" endowed with color (Works V 319: S 34). For attempts to pin Boyle down to a more specific metaphysics of sensible qualities, see Anstey 2000, Kaufman 2006. I agree with Anstey that in the end Boyle's metaphysical commitments here are not as precise as we might like.
} 
hypothetical, Boyle wants to defend the claim that we needn't adopt the commonly imagined view, for corpuscularian doctrine shows us how our experience can be explained without doing so. Further, although Boyle sincerely held that the hypothesis required further confirmation, he also maintained that it had received considerable confirmation already, and was explanatorily superior to its main competitors: Aristotelian physics and Paracelsian chemistry.

In About the Excellency and Grounds of the Mechanical Hypothesis, Boyle explicitly develops a case for the explanatory virtues of corpuscularianism, and thus for the claim that we ought, if possible, to attribute to bodies only primary affections. Boyle lauds corpuscularianism for the (purported) fact that its principles are few, clear (familiar from sense perception), ${ }^{49}$ primary and simple (basic, irreducible), and comprehensive (able to explain all sorts of phenomena). Most interesting are Boyle's claims for the uniqueness of corpuscularianism, which can be condensed into the slogan, "by what ever Principles Natural things be constituted, 'tis by the Mechanical Principles that their Phænomena must be clearly explicated” (Works VIII 113: S 150). Boyle's most extended defense of this slogan comes at the end of the work:

These Principles, Matter, Motion (to which Rest is related) Bigness, Shape, Posture, Order, Texture being so simple, clear, and comprehensive, are applicable to all the real Phaenomena of Nature, which seem not to be explicable by any other not consistent with ours. For, if recourse be had to an Immaterial Principle or Agent, it may be such an one, as is not intelligible; and however it will not enable us to explain the Phenomena, because its way of working upon things Material would probably be more difficult to be Physically made out, than a Mechanical account of the Phonomena. And, notwithstanding the Immateriality of a created Agent, we cannot conceive, how it should produce changes in a Body, without the help of Mechanical Principles, especially Local Motion...

And if the Agents or active Principles resorted to, be not Immaterial, but of a Corporeal Nature, they must either in effect be the same with the Corporeal Principles above-nam'd; or, because of the great Universality \& Simplicity of ours, the new ones propos'd must be less general than they, and consequently capable of being subordinated or reduc'd to ours... So that the fear, that so much of a New Physical Hypothesis, as is true, will overthrow or make useless the Mechanical Principles, is as if one should fear, that there will be a Language propos'd, that is discordant from, or not reducible to, the Letters of the Alphabet.

(Works VIII 116: S 153-4)

An immaterial agent will "probably" leave its manner of working on material bodies unexplained. While this is not indisputable, the legacy of Cartesian dualism surely renders it compelling. But why can't nonmechanical material/corporeal principles do explanatory work? A first question here is: what all does Boyle include under the heading of mechanical principles? If we collapse "mechanical" into "matter and motion," as Boyle often does in Excellency and Grounds, then it could turn out to be

\footnotetext{
49 Thus, although Boyle agrees with Descartes in holding that clarity distinguishes the corpuscularian primary affections from other purported qualities of bodies, the notion of clarity to which he appeals is distinctively empiricist, and contrasts with Descartes' appeal to the clarity and distinctness of geometry.
} 
trivially true that any material principle must be a mechanical principle. It is clear, though, that Boyle's understanding of matter, though less explicitly spelled out here, remains the specific and spare one of Origin of Forms and Qualities, a substance extended and impenetrable. He is claiming, then, that any proposed corporeal principles are ultimately resolvable into extension, impenetrability, size, shape, motion, rest, texture. What Boyle has in mind here are chemical principles, such as salt or mercury, which he holds may be genuine agents, but agents that work in virtue of their specific corpuscularian microstructures.

How might his argument apply to sensible qualities such as redness? Boyle asserts that if colors are corporeal, they must be identical with, or reducible to, mechanical qualities, because of the simplicity and universality of mechanical principles. In claiming that the mechanical principles are simple, he claims that they are basic, foundational, and not complex. The reason for this is that we cannot conceive of them being reduced to other, more basic qualities. This conceptual point is challengeable (might we imagine size being reduced to location plus repulsive force?), but certainly intuitive. The mechanical principles are universal because they are present in all of matter, a point supported well enough by simple induction. But what grounds are offered here for excluding the sensible qualities from bodies? Why not suppose that redness (or saltiness, for that matter) is also a basic quality, irreducible to mechanical primary affections? It is not at all obvious that Boyle has any further argument here. He has offered no grounds for claiming that the mechanical affections exhaust the simple qualities. He might hold that neither color ${ }^{50}$ nor flavor are universal, and that this is a reason to exclude them from bodies. But this works only via the question-begging mechanist assumption that matter is catholic, that is, that material stuff is everywhere the same, differentiated only by motion, size, shape, arrangement. If we bar this, as we should, all Boyle has to appeal to is comprehensiveness as spelled out in the alphabet analogy - mechanism has plenty of resources at its disposal, and offers prospects for explaining saltiness and redness without the need to posit additional qualities.

It seems, then, that we have located little beyond Ockham's razor to anchor the stripping of sensible qualities from bodies. When we ask, why ought we to deny that sensible qualities are really in bodies as we might naively take them to be, the best response we get is that we have an attractive hypothesis in corpuscularianism which promises to explain them away in terms of merely mechanical affections.

There is one more point in Boyle, however, which we have so far passed over, and which deserves to be explored. When Boyle discusses corpuscularianism's purportedly unique ability to explain how change is effected, he frequently alludes to motion:

\footnotetext{
${ }^{50}$ As with Descartes' apparent argument from elimination in Pr II 4 and 11, this argument is a nonstarter if one holds, with Berkeley, that there are no uncolored bodies, and that "pellucidness" is a color. (See entry 453 of Berkeley's notebooks, Berkeley 1948-57, I 56.) Further, if motion-or-rest (or mobility) is to count as a universal quality, why not count colored-or-uncolored?
} 


\section{I32 PRIMARY AND SECONDARY QUALITIES}

... the Mechanical Philosopher being satisfied, that one part of Matter can act upon another but by vertue of Local Motion, or the effects and consequences of Local Motion, he considers, that as, if the propos'd Agent be not Intelligible and Physical, it can never Physically explain the Phanomena...

(Works VIII 109: S 145)

To be short, if we fancy any two of the Bodies about us, as a Stone, a Mettal, \&c., to have nothing at all to do with any other Body in the Universe, 'tis not easy to conceive, either how one can act upon the other, but by Local Motion (of the whole Body, or its Corporeal Effuvia;) or how by Motion it can do any more, then put the Parts of the other Body into Motion too, and thereby produce in them a Change of Scituation and Texture, or of some other of its Mechanical Affections: though this (Passive) Body being plac'd among other Bodies in a World constituted as ours now is, and being brought to act upon the most curiously contriv'd Sensories of Animals, may upon both these accounts exhibit many different sensible Phanomena; which however we look upon them as distinct Qualities, are consequently but the Effects of the often mention'd Catholick affections of Matter, and deducible from the Size, Shape, Motion (or Rest,) Posture, Order, and the resulting Texture, of the Insensible parts of Bodies.

(Works V 321: S 36)

In both of these passages, Boyle is engaging in understatement. He doesn't simply hold that the mechanical philosopher is satisfied that matter can act only by local motion, he thinks that we all ought to be so satisfied. He doesn't simply think that it isn't easy to conceive of how one body can act upon another but by local motion, but that no other manner of action is in fact conceivable by us. Locke put the same thought more boldly in the first edition of the Essay, 2.8.11.: ${ }^{51}$

The next thing to be consider'd, is how Bodies operate one upon another, and that is manifestly by impulse, and nothing else. It being impossible to conceive, that Body should operate on what it does not touch, (which is all one has to imagine it can operate where it is not) or when it does touch, operate any other way than by Motion.

(Locke 1975, 135)

If we cannot conceive of bodies as acting except by motion, then it looks as though corporeal sensible qualities must be otiose, for we cannot explain how redness as a basic, non-mechanical quality could be transmitted from object to perceiver. The upshot is not that bodies could not be really red, nor that it is (as Descartes had it) unintelligible to suppose that they are really red, but that the posit that they are really red can do no explanatory work, since any explanation of sense perception would have to trace back to mechanically produced motion. Thus this conclusion is stronger than the mere claim that we ought not to posit real corporeal sensible qualities because we have a superior theory (simpler, clearer, more reductive, etc.) without them. The purported conclusion is that we cannot posit sensible qualities if we want to formulate a legitimate hypothesis in natural philosophy, one that can do explanatory work.

\footnotetext{
${ }^{51}$ He was famously forced to modify this claim by the example of Newton, as he acknowledges to Stillingfleet (Locke 1823, IV 467-8).
} 
This ought to remind us of an argument of Descartes' that was dismissed as questionbegging at the end of section 3. Descartes' emphasis there, in Part IV of the Principles, was on the implications of neurophysiology for the sensible qualities. And this strategy I accused of circularity if the goal is to argue that bodies don't have real sensible qualities, rather than merely that we may be able to explain sensory experience without positing any such qualities. The circularity arises because Descartes' neurophysiological views look uncontroversial only in a mechanist context; thus his neurophysiology can't be used to support the foundations of his mechanism. The second half of the passage, however, floats free of the details of neurophysiology and looks very much like Boyle's attempts to make a conceptual point about motion and the sensible qualities:

Finally, let us consider heat and other qualities perceived by the senses, in so far as those qualities are in objects, as well as the forms of purely material things, for example the form of fire: we often see these arising from the local motion of certain bodies and producing in turn other local motions in other bodies. Now we understand very well how the different size, shape and motion of the particles of one body can produce various local motions in another body. But there is no way of understanding how these same attributes (size, shape and motion) can produce something else whose nature is quite different from their own-like the substantial forms and real qualities which many $<$ philosophers $>$ suppose to inhere in things; and we cannot understand how these qualities or forms could have the power subsequently to produce local motions in other bodies. Not only is all this unintelligible, but we know that the nature of our soul is such that different local motions are quite sufficient to produce all the sensations in the soul. What is more, we actually experience the various sensations as they are produced in the soul, and we do not find that anything reaches the brain from the external sense organs except for motions of this kind. In view of all this we have every reason to conclude that the properties in external objects to which we apply the terms light, colour, smell, taste, sound, heat and cold ... are, so far as we can see, simply various dispositions in those objects which make them able to set up various kinds of motions in our nerves $<$ which are required to produce all the various sensations in our soul $>$.

(Pr IV 198)

Descartes writes here about what we can and cannot understand, but the point is quite different from his Pr I 66-71 argument. The claim here is not that it is unintelligible to suppose that bodies have real corporeal sensible qualities, but rather that, if we make that posit, we cannot use it to explain sensory experience.

Having located a common argument here, what should we think of it? Surely what Boyle and Descartes succeed in doing here is simply issuing an explanatory challenge: If sensible qualities such as redness are real corporeal qualities, it must be explained how such further qualities engage with motion, and it is quite unobvious what such an explanation would look like. ${ }^{52}$ Both Boyle and Descartes overreach by claiming that

\footnotetext{
52 It is worth remembering that the Scholastics thought they had given such an explanation, by way of intentional species, though their modern detractors typically regarded it as unworthy of serious attention. Malebranche (1980, 220-221) does devote a few pages of his extensive treatment of vision in the Search After Truth to refuting it. Boyle treats the theory contemptuously in Things Above Reason. It is presented as a possible reductio of the category of things above reason - if we must admit things above reason, will we end up
} 


\section{I34 PRIMARY AND SECONDARY QUALITIES}

no such explanation can be given. ${ }^{53}$ Boyle, characteristically, refrains from a further sort of (Cartesian) overreaching on this point, claiming only to have revealed what we can and cannot understand, not what must be the case. For Boyle, the physical world may well transcend mechanism (and thus transcend the corpuscularian list of primary affections), but to the extent that it does, we will never be able to fully comprehend it:

... I see no necessity, That Intelligibility to a humane Understanding, should be necessary to the Truth or Existence of a thing; any more then that Visibility to a Humane Eye, should be necessary to the Existence of an Atome, or of a Corpuscle of Air...

(Works IX 398-9) $)^{54,55}$

\section{Bibliography}

Anstey, P. (2000). The Philosophy of Robert Boyle, London: Routledge.

Berkeley, G. (1948-1957). 9 vols, ed. A. A. Luce and T. E. Jessop. The Works of George Berkeley,

Bishop of Cloyne, London: Thomas Nelson and Sons.

Boyle, Robert. (1991). Selected Philosophical Papers of Robert Boyle, Indianapolis: Hackett.

- (1999-2000). The Works of Robert Boyle, London: Pickering and Chatto.

Buroker, J. V. (1991). “Descartes on Sensible Qualities," Journal of the History of Philosophy 29(4): 585-611.

Clarke, D. (1989). Occult Powers and Hypotheses, Oxford: Oxford University Press.

Cook, M. (1996). "Descartes and the Dustbin of the Mind," History of Philosophy Quarterly 13: $17-33$.

Cottingham, J. (1989-1990). "Descartes on Colour," Proceedings of the Aristotelian Society 90: 231-246.

De Rosa, R. (2007). “The Myth of Cartesian Qualia,” Pacific Philosophical Quarterly 88: 181-207. Des Chene, D. (1996). Physiologia, Ithaca: Cornell University Press.

Descartes, R. (1984-1991). The Philosophical Writings of Descartes. 3 vols, ed. and trans. J. Cottingham, R. Stoothoff, D. Murdoch, A. Kenny, Cambridge: Cambridge University Press. — (1996). Euvres de Descartes. 11 vols, ed. C. Adam and P. Tannery. Paris, J. Vrin.

Garber, D. (1992). Descartes' Metaphysical Physics, Chicago: University of Chicago Press.

believing in intentional species (Works IX 407)? The answer, I take it, is that we won't because no good positive arguments have been presented in favor of intentional species and it is therefore a "precarious Tenet" (Works IX 408). One charitable contemporary commentator, Alison Simmons (1994, 153), ultimately concludes: "Unfortunately, species nevertheless turn out to be physical and metaphysical anomalies within the Aristotelian framework."

53 Cottingham (1989-90) justifies Descartes' move here as an application of a "Causal Similarity Principle," but I am reluctant to attribute CSP to Descartes.

54 Of course, this is too forthright to be in Boyle's own voice. He is speaking through the dialog character Eugenius. The topic is things above reason, but Boyle holds that this category is not exhausted by the divine, but also includes aspects of the corporeal world.

${ }^{55}$ I am grateful to Abe Roth and Daniel Sutherland for helpful comments at an early stage of this paper's existence. I have also benefited from comments (on sections 2-6) from audiences at USC (especially Mathias Frisch), NIU, Notre Dame, U. of Cincinnati, and the New England Colloquium in Early Modern Philosophy, as well as from students in Descartes seminars at UIC and OSU. Thanks also to two anonymous referees for Oxford University Press whose comments improved the paper. 
(2001). "Forms and Qualities in the Sixth Replies," in Descartes Embodied. Cambridge: Cambridge University Press: 257-273.

Hume, D. (1978). A Treatise of Human Nature, ed. P. H. Nidditch and L. A. Selby-Bigge, Oxford: Clarendon Press.

- (2000). A Treatise of Human Nature, ed. D. F. Norton and M. J. Norton, Oxford: Oxford University Press.

Kaufman, D. (2006). "Locks, Schlocks, and Poisoned Peas: Boyle on Actual and Dispositive Qualities," Oxford Studies in Early Modern Philosophy (3): 153-198.

_ (2008). "Descartes on Composites, Incomplete Substances, and Kinds of Unity," Archiv für Geschichte der Philosophie 90: 39-73.

Keating, L. (2004). "The Role of the Concept of Sense in Principles IV, 189-98," British Journal for the History of Philosophy 12(2): 199-222.

La Forge, L. de (1666). Traité de l'esprit de l'homme, Amsterdam: Abraham Wolfgang. (Reprint edition: Hildesheim: Georg Olms Verlag, 1984).

Locke, J. (1823). The Works of John Locke, 10 vols, London: Thomas Davison, Whitefriars.

— (1975) An Essay Concerning Human Understanding, ed. P. H. Nidditch, Oxford: Clarendon Press.

Malebranche, N. (1958-1967). Oeuvres Complètes de Malebranche, 20 vols, ed. André Robinet, Paris: J. Vrin.

- (1980). The Search After Truth, trans. T. Lennon and P. Olscamp, Columbus: The Ohio State University Press.

Menn, S. (1995). “The Greatest Stumbling Block: Descartes’ Denial of Real Qualities,” Descartes and his Contemporaries: Meditations, Objections, and Replies, R. Ariew and M. Grene, Chicago: University of Chicago Press: 182-207.

Rozemond, M. (1998). Descartes's Dualism, Cambridge: Harvard University Press.

Sanford, D. H. (2002). "Determinates vs. Determinables," The Stanford Encyclopedia of Philosophy, E. Zalta. http://plato.stanford.edu/archives/sum2002/entries/determinate-determinables/

Secada, J. (2000). Cartesian Metaphysics: The Late Scholastic Origins of Modern Philosophy, Cambridge: Cambridge University Press.

Simmons, A. (1999). “Are Cartesian Sensations Representational?”, Noûs 33(3): 347-369.

— (1994). "Making Sense: The Philosophical Treatment of Phenomenal Qualities from the Late Aristotelians to Descartes," Philosophy, Philadelphia: University of Pennsylvania.

Wilson, M. (1999). "Descartes on the Representationality of Sensation," Ideas and Mechanism: Essays on Early Modern Philosophy, Princeton: Princeton University Press: 69-83. 